\title{
The Development of Polymer-Based Flat Heat Pipes
}

\author{
Christopher Oshman, Bo Shi, Chen Li, Ronggui Yang, Member, IEEE, Y. C. Lee, \\ G. P. Peterson, and Victor M. Bright, Senior Member, IEEE, Fellow, ASME
}

\begin{abstract}
In this paper, polymer-based flat heat pipes (PFHPs) with a thickness on the order of $1 \mathrm{~mm}$ have been successfully developed and tested. Liquid-crystal polymer (LCP) films with copper-filled thermal vias are employed as the case material. A copper micropillar/woven mesh hybrid wicking structure was designed and fabricated to promote evaporation/condensation heat transfer and the liquid supply to the evaporator of the PFHP. Water was selected as the working fluid because of its superior thermophysical properties. An experimental study was conducted to examine the PFHP performance. The test data demonstrated that the PFHP can operate with a heat flux of $11.94 \mathrm{~W} / \mathrm{cm}^{2}$ and results in effective thermal conductivity ranging from 650 to $830 \mathrm{~W} / \mathrm{m} \cdot \mathrm{K}$, with the value varying with the input heat flux and the tilt angle. With the employment of flexible LCP as casing material, the PFHP could potentially be directly integrated into a printed circuit board or flexible circuits for thermal management of heat-generating components.

[2010-0280]
\end{abstract}

Index Terms-Cooling, flat heat pipe (FHP), hybrid wick, polymer.

\section{INTRODUCTION}

A HEAT PIPE is a sealed vessel containing working fluids, such as water, acetone, etc. Through the use of efficient two-phase heat-transfer loop, the thermal resistance of a heat pipe can be several orders of magnitude lower than that of the best solid conductors, such as copper and aluminum. As such, heat pipes have been widely used in modern industries and commercial products as important thermal-management components [1]-[8].

The working mechanism of a flat heat pipe (FHP) is the same as that of conventional heat pipes with cylindrical geometries [9]. Heat enters the wicking structure of the evaporator section through the casing material, and the liquid saturating the wick absorbs the heat and vaporizes. The vapor flows from the hot

Manuscript received September 25, 2010; revised November 30, 2010; accepted December 6, 2010. Date of publication February 14, 2011; date of current version April 1, 2011. This work was supported in part by the Defense Advanced Research Projects Agency Thermal Ground Plane Program managed by Dr. Tom Kenny (N66001-08-C-2006), in part by the Nanotechnology Infrastructure Network at the Colorado Nanofabrication Laboratory, and in part by the National Science Foundation under Grant ECS-0335765. Subject Editor N. F. de Rooij.

C. Oshman, R. Yang, Y. C. Lee, and V. M. Bright are with the Department of Mechanical Engineering, University of Colorado at Boulder, Boulder, CO 80309 USA (e-mail: victor.bright@ colorado.edu).

B. Shi was with the University of Colorado at Boulder, Boulder, CO 80309 USA. He is now with the School of Energy and Power Engineering, Nanjing University of Science and Technology, Nanjing 210094, China.

C. Li was with the University of Colorado at Boulder, Boulder, CO 80309 USA. He is now with the School of Mechanical Engineering, University of South Carolina, Columbia, SC 29208 USA.

G. P. Peterson was with the University of Colorado at Boulder, Boulder, CO 80309 USA. He is now with the School of Mechanical Engineering, Georgia Institute of Technology, Atlanta, GA 29208 USA.

Digital Object Identifier 10.1109/JMEMS.2011.2107885 evaporator to the cold condenser due to the vapor-pressure differential and condenses, releasing its latent heat of vaporization. The condensate accumulates in the capillary structures (grooves, mesh, or other porous media) and is pumped back to the hot evaporator by capillary pressure, enabling a continuous liquid-vapor cycle. Through this passive process, heat is efficiently transported from the hot evaporation region to the cold condensation region with a very small temperature difference.

FHPs with different wicking structures and materials have been developed and tested in the past two decades. In 1990, Adami and Yimer [10] constructed a $15.24 \mathrm{~cm} \times 30.48 \mathrm{~cm} \times$ $1.905 \mathrm{~cm}$ FHP with water as the working fluid and three layers of \#100 copper mesh as the wicking material. They found that gravitational orientation did not have a significant effect on the performance, and the axial temperature gradient increased nearly linearly with input power. Ogushi et al. [11] also conducted an investigation on a similar device. This device had a $2.5-\mathrm{mm}$-thick vapor core with axial grooves as the wicking structure to distribute the working fluid (methanol or ammonia) throughout the heat pipe and a sharp-edged corner for working-fluid communication between the top and bottom plates. Although some problems with slugging were encountered, the overall temperature drop when using methanol as the working fluid was about half of the temperature drop when compared with an aluminum plate of the same dimensions and only one-fourth of that when using ammonia as the working fluid. In 2002, Shimura et al. [12] manufactured an aluminumbased FHP with cyclopentane as working fluid. This device transferred a heat flux of $5 \mathrm{~W} / \mathrm{cm}^{2}$.

With ever-increasing integration complexity, cooling devices must be of high efficiency, along with compact size, to meet the cooling needs of miniaturized modern electronic devices. "Microheat pipes" with dimension characteristics of [13]

$$
\frac{r_{c}}{r_{h}} \geq 1
$$

where $r_{c}$ is the capillary radius and $r_{h}$ is the hydraulic radius, were first introduced by Cotter [14] in 1984. To date, investigations have been conducted on many different types of micro FHPs. In 2002, Moon et al. [15] pressed a copper-based cylindrical microheat pipe of 4-mm diameter with woven-wire wick to a planar structure for notebook PC cooling. They found that the heat pipe worked normally when the pressed thickness was between 2.5 and $3.0 \mathrm{~mm}$. However, the cooling performance was significantly decreased when it was pressed to less than $2 \mathrm{~mm}$. In 2005, Wang and Peterson [16] built a novel FHP using wires, mesh, and foils. Two prototypes with different wick configuration were evaluated. They found that the maximum heat flux was as high as $19.1 \mathrm{~W} / \mathrm{cm}^{2}$. As expected, 
the heat flux varied with mesh number, wire diameter, number of layers, sintering process, and tilt angle. When the tilt angle was from $50^{\circ}$ to $60^{\circ}$, the performance was only from one-fourth to one-fifth of the horizontal case. More recently, Lim et al. [17] have designed a flat copper microheat pipe, which was able to transfer $8 \mathrm{~W}$ under adverse gravity conditions in which the evaporator was situated above the condenser.

Most of the aforementioned FHPs were constructed using thermally conductive materials (such as metals, silicon, etc.) because of their advantage of high thermal conductivity and high strength. In general, the metal cases have a low thermal resistance for transferring heat into and out of heat pipes. Additionally, it is comparably easy to achieve high hermetic sealing on metals to enable a highly reliable heat pipe. However, it is very challenging to develop flexible or nonelectrically conductive heat pipes for some special applications based on the process developed for metals. Researchers have been looking for solutions to develop polymer-based FHPs (PFHPs). The PFHP has advantages, such as low cost, lightweight, flexibility, and dielectric property, over traditional metal-cased heat pipes. In 2001, a flexible polymer-based microheat pipe was proposed and analyzed for use in space applications [18]. The theoretical analysis of the PFHP predicted an effective thermal conductivity of $740 \mathrm{~W} / \mathrm{m} \cdot \mathrm{K}$ with a length of $16.4 \mathrm{~cm}$ and a groove width of $30 \mu \mathrm{m}$. However, a prototype has not yet been produced.

Liu et al. [19] fabricated and tested a polymer-based heat pipe for integrated-circuit cooling applications. The device was conical in shape and fabricated using a photosensitive resin and a sintered metal/resin capillary structure. Interestingly, their device is integrated on chip directly to reduce the contact thermal resistance. However, the authors did not report the performance quantitatively. In 2002, Jones et al. [20] reported microheat pipes embedded in laminated ceramic substrates, based on a microgroove wicking structure realized by stacking dielectric layers in a staggered lay up. In this case, heat-pipe failure occurred around $10 \mathrm{~W}$ due to delamination of the printed circuit board (PCB). In 2006, Wits et al. [21] also built an FHP using standard PCB materials and processing. It reached $12 \mathrm{~W}$ of power transmission; however, this heat-pipe substrate was still rigid.

In this paper, the goal is to demonstrate a liquid-crystalpolymer (LCP)-based PFHP with superior thermal performance. The architecture of this newly developed PFHP is similar to a traditional metal-cased FHP [9]. The test data show that the PFHP can operate with a heat flux of $11.94 \mathrm{~W} / \mathrm{cm}^{2}$ with effective thermal conductivity from 650 to $830 \mathrm{~W} / \mathrm{m} \cdot \mathrm{K}$, which varies with the input heat flux and the tilt angle. This experimental study shows that the performance of the PFHP can be competitive with traditional FHPs. In addition, our PFHP can potentially be directly integrated into a PCB or flexible circuits as thermal-management components.

\section{DESIGN AND FABRICATION OF PFHP}

\section{A. Design of PFHP}

The cross-sectional and bottom view of our PFHP design is shown in Fig. 1.

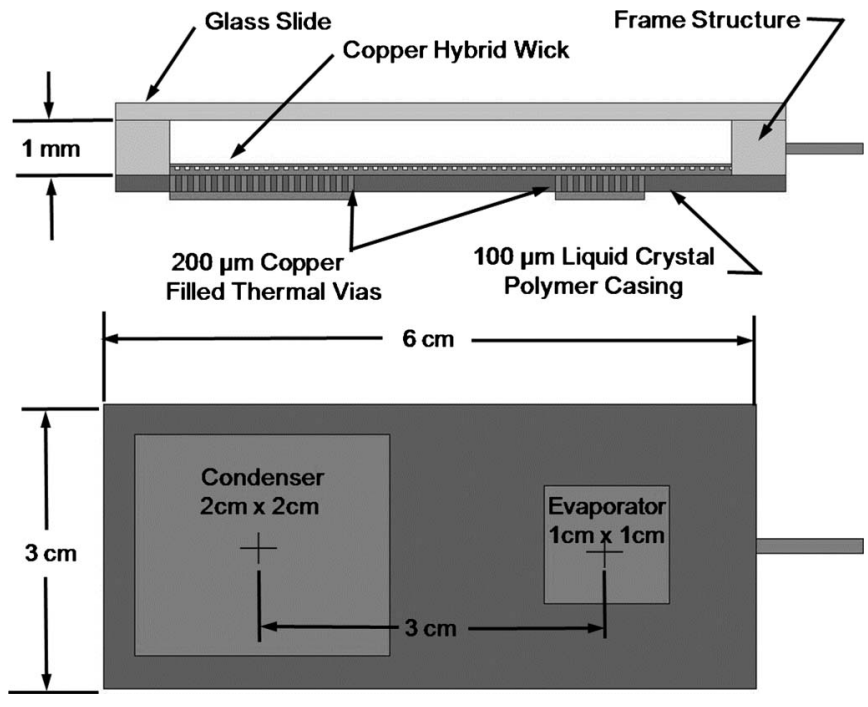

Fig. 1. Cross-sectional and bottom view schematic of LCP-cased FHP.

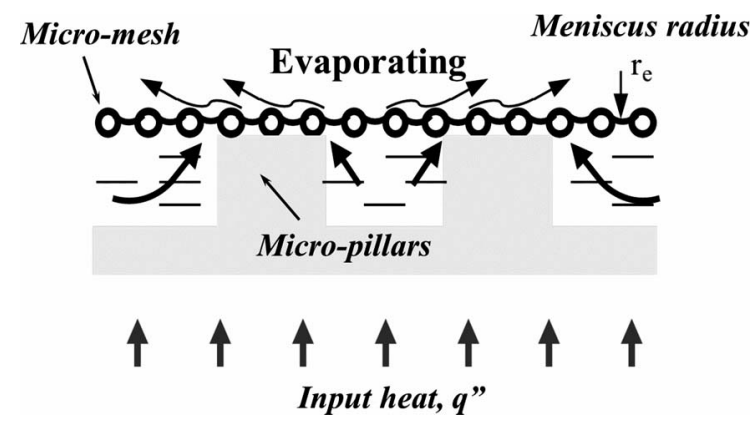

Fig. 2. Diagram of the copper hybrid wicking structure used in the PFHP composed of $200-\mu \mathrm{m}$-wide grooves topped with \#200 woven copper mesh.

Similar to a conventional FHP, the PFHP has a rectangular encasing, an evaporator, and a condenser with wicking structures. We chose flexible LCP as the casing material for several reasons. It is highly hermetic [22] and exhibits moisture absorption of $0.02 \%$ versus the $2.8 \%$ for that of Kapton polyimide film [23]. The $x-y$ coefficient of thermal expansion of LCP film is controllable to be anywhere between 0 to $30 \mathrm{ppm} / \mathrm{K}$, whereas that of the Kapton polyimide is fixed at $20 \mathrm{ppm} / \mathrm{K}$, allowing the possibility of nearly stress-free bonding and operation of heat-generating components. LCP is also highly resistant to chemical attack and is able to withstand prolonged exposure to most acids, bases, and solvents [24].

However, the thermal conductivity of LCP is relatively low $(\sim 0.2 \mathrm{~W} / \mathrm{m} \cdot \mathrm{K})$ as compared with those of metals typically used in heat-pipe fabrication. To reduce the thermal resistance of the case, copper-filled thermal vias are thus fabricated in the evaporating and condensing areas, as shown in the bottom view of Fig. 1.

Conventional FHPs with uniform wick structures, such as grooves, sintered mesh, or particles, are not suitable for high heat-flux applications. This is because the flow resistance from the sintered mesh or particles is high, which generally results in a low maximum heat load. In this paper, a hybrid wick structure, shown in Fig. 2, was developed and fabricated to overcome this disadvantage of uniform wicks. 


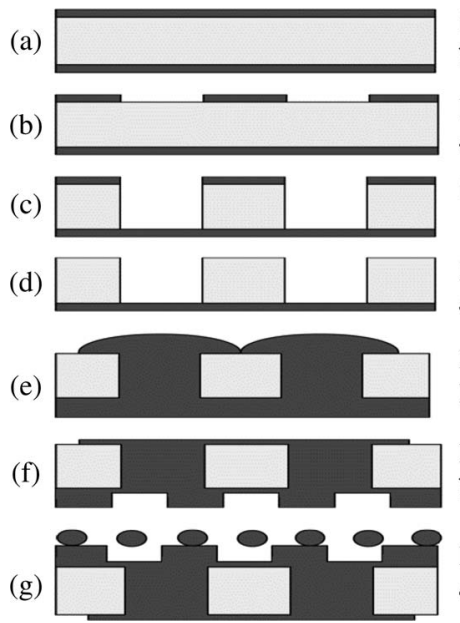

$100 \mu \mathrm{m}$ LCP with $18 \mu \mathrm{m}$ copper on both sides.

Photolithography and wet etching of Cu via mask.

Reactive Ion Etch through the LCP.

Remove the top Cu layer with wet etching.

Electroplate the vias up through the LCP.

Polish the $\mathrm{Cu}$ vias and etch the bottom liquid flow channels.

Bond the woven Cu mesh to the channels with electroplating.

Fig. 3. Fabrication-process steps of copper-filled thermal vias in LCP and hybrid wicking structure [26].

The hybrid wick is composed of a single layer of woven copper mesh $\left(200 \mathrm{in}^{-1}\right)$ bonded to the top of $200-\mu \mathrm{m}$ capillary grooves. This mesh has been chosen for its relatively low cost and abundance in industry while still providing a strong capillary pumping pressure to drive the viscous flow. The $200-\mu \mathrm{m}$-wide capillary grooves of the hybrid structure allow liquid flow with small viscous pressure loss.

This hybrid structure is believed to effectively enhance heat transfer by inducing film evaporation on the mesh and reducing the flow resistance resulting from returned liquid working flow.

\section{B. Fabrication of PFHP}

The fabrication of the flat polymer heat pipe begins with $100-\mu$ m-thick LCP with $18-\mu \mathrm{m}$ copper thermally bonded to each side (Rogers Corporation, Ultralam 8035), as shown in Fig. 3(a).

Copper-filled thermal vias are formed in the evaporator and condenser sections to improve the thermal conductivity of the LCP casing material. The three-layer material is fixed to a silicon wafer with adhesiveless semiconductor tape. Positive photoresist (PR) is spun on the copper, and a negative image of the desired vias is patterned on the PR. For this device, the evaporator is $1 \mathrm{~cm}^{2}$, and the condenser is $4 \mathrm{~cm}^{2}$. The thermal vias with $200-\mu \mathrm{m}$ diameter are patterned in a hexagonal array with $200-\mu \mathrm{m}$ spacing. The exposed via holes on the top copper layer are etched through with liquid copper etchant (CE-200), as shown in Fig. 3(b). Reactive ion etching was used to cut the via holes in the polymer since a suitable liquid-polymer etchant could not be found. The process was completed using plasma with 16 standard cubic centimeter per minute (SCCM) of $\mathrm{CF}_{4}$ and $4 \mathrm{SCCM}$ of $\mathrm{O}_{2}$, which is a standard recipe used in our reactor.

It has however been demonstrated in literature [25] that a pure $\mathrm{O}_{2}$ can decrease the etch time of polymers by as much as one-half. The top copper layer served as an etch mask, and the bottom layer served as an etch stop, as shown in Fig. 3(c). It took a total $10 \mathrm{~h}$ to cut through the $100-\mu \mathrm{m} \mathrm{LCP}$ using 1-h exposures to avoid excessive heating. Despite this prolonged plasma exposure, the material did not experience

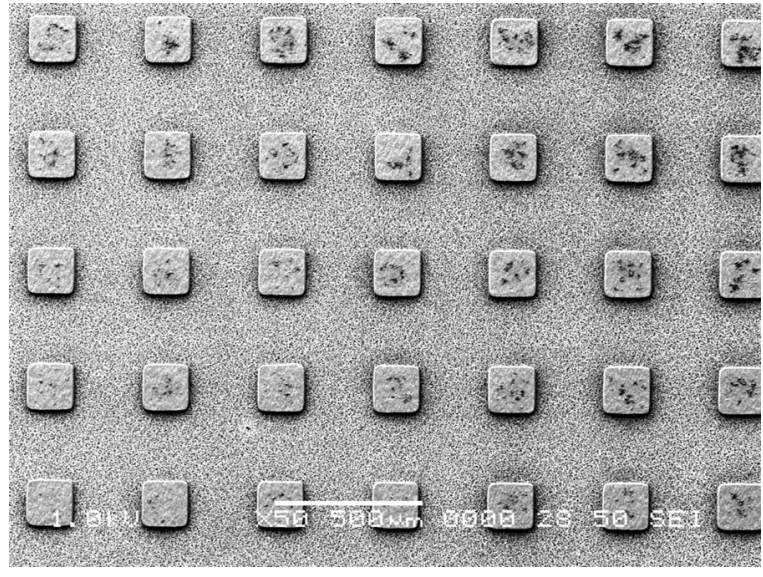

Fig. 4. Scanning electron microscope image of the copper wet-etched 200- $\mu \mathrm{m}$ evaporator wicking channels.

any deformation and displayed an undercutting of $10 \mu \mathrm{m}$ with no noticeable deterioration or delamination of the copper-mask layer. The top layer of copper is then removed with wet etchant. Although not shown in Fig. 3(d), the copper on the bottom of the via hole was protected with an additional layer of PR during the wet-etching process. The vias are then filled with copper from the bottom up using electroplating. The copper is allowed to overplate above the LCP to form a continuous pad for the evaporator and condenser sections, as shown in Fig. 3(e).

The microchannels for liquid transport are formed by first electroplating the bottom copper layer from 18 to $100 \mu \mathrm{m}$ and then using photolithography and wet etching to define $200-\mu \mathrm{m}$ wide by $80-\mu \mathrm{m}$ deep pillars, as seen in Fig. 4. Pillars are chosen, rather than channels, to allow liquid to return to the evaporator from any direction and achieve uniform liquid distribution in the evaporating area. A single layer of $7874 \mathrm{~m}^{-1}\left(200 \mathrm{in}^{-1}\right)$ woven copper mesh is then pressed uniformly to the top of the formed pillars and then bonded by electroplating to create a hybrid wicking structure, as shown in Fig. 3(g). The advantage of the hybrid wicking structure is its low flow resistance and high capillary pumping pressure. A $20-\mu \mathrm{m}$ layer of copper remains to line the inside of the PFHP to serve as a gas and liquid diffusion barrier due to the low permeability of LCP. More details of the fabrication process may be found in Oshman et al. [26].

To achieve compactness, researchers have been trying to reduce the FHP thickness and maintain its performance at the same time. As discussed in the Introduction Section, the FHP performance was found to decrease with its thickness due to the fact that the vapor flow resistance would increase significantly with decreasing thickness of the vapor core. In the development of PFHP, the vapor-core thickness is carefully managed to be approximately $1.0 \mathrm{~mm}$.

A 1-mm-thick 5-mm-wide copper frame and small polymer spheres are used to support the flexible layer and maintain an adequate vapor space. A glass slide is placed on top to enable visualization of the liquid flow. The charging tube is a 1.016-mm (0.04-in)-diameter copper tube. The top and bottom views are seen in Fig. 5.

We note that the current prototype device, as tested, was in a rigid configuration, while it has great potential to be made 


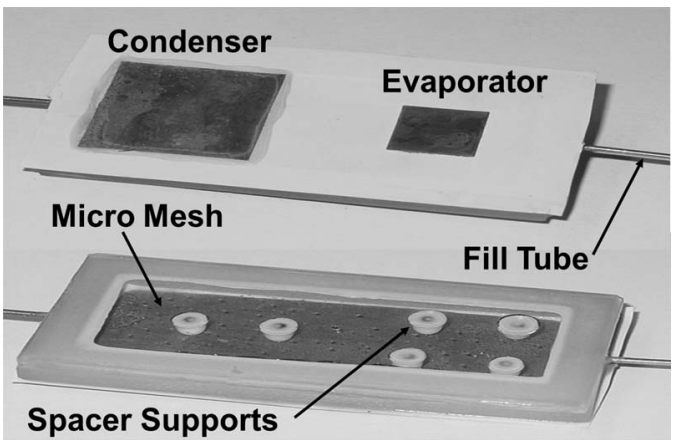

Fig. 5. Top and bottom views of the finished PFHP showing the evaporator and condenser regions located on the LCP substrate.

flexible. Research has shown that the effect of bending an originally straight heat pipe up to $90^{\circ}$ has a negligible effect on the vapor-pressure loss and little effect on the temperature difference between the evaporator and the condenser. It was found out that bending of compressible wicking structures may however obstruct the liquid flow to the evaporator and decrease the capillary limit and, consequently, the maximum heat-transport ability of the device [27].

After assembly and before charging, the PFHP was cleaned to remove contaminants. The cleaning step has been found to minimize the noncondensable gases and improve the contact condition between the wicking and working fluid, therefore increasing the capillary pressure. The cleaning process involved using a vacuum pump to flush a $10 \% \mathrm{H}_{2} \mathrm{SO}_{4}$ solution through the uncharged PFHP. This cleaning process ran for $15 \mathrm{~min}$ to ensure an oxide-free copper surface. Deionized water was then drawn through the device for another 15 min for several times to rinse the internal surface. Once thoroughly rinsed several times, the heat pipe was then placed in a vacuum oven at $100^{\circ} \mathrm{C}$ and $100 \mathrm{mtorr}$ for $30 \mathrm{~min}$ to remove the residual moisture from the wicking structure. The copper charging tube was connected to a turbomolecular vacuum pump until the pressure reached $10^{-7}$ torr for $24 \mathrm{~h}$, which is sufficient for all of the materials in the heat pipe to be outgassed. The evacuated heat pipe was then accurately charged with $0.198 \mathrm{ml}$ of distilled and degassed water.

\section{EXPERIMENTAL CHARACTERIZATION}

\section{A. Experimental Study of PFHP}

Five prototypes of our PFHPs have been fabricated for experimental studies. The test facility is shown schematically in Fig. 6.

A $1 \mathrm{~cm} \times 1 \mathrm{~cm}$ ceramic heater is positioned at the bottom of the evaporation region. Due to the flexible nature of the LCP film, the applied pressure on the heater is limited to approximately $50 \mathrm{kPa}$. Thermal grease is layered between the heater and the evaporator to reduce the contact thermal resistance. A dc power supply (Agilent E3620A) is used to supply power to the heater. The input power (voltage and current) of the heater is directly recorded for reference. It should be noted that this power is generally higher than the actually transported power because of the heat loss dissipated through the thermal insula-

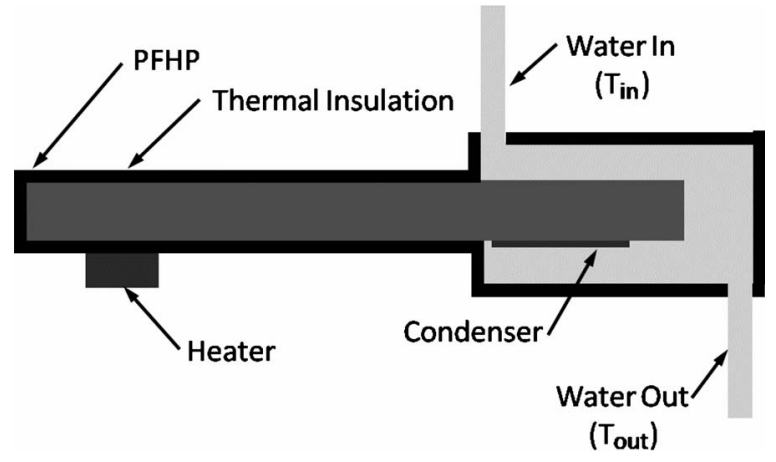

Fig. 6. PFHP testing setup using a water heat exchanger in the condenser section to determine the heat transferred by the device.

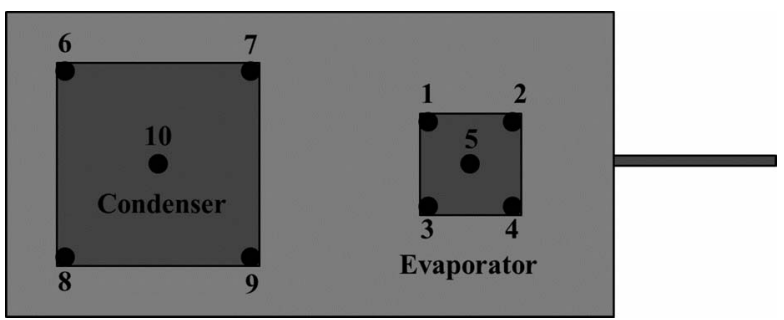

Fig. 7. Thermocouple arrangement on the evaporator and condenser for characterizing the PFHP.

tion layer. The condensation region is cooled by a single-phase water heat exchanger. The inlet temperature $\left(T_{\mathrm{in}}\right)$ and outlet temperature $\left(T_{\text {out }}\right)$ of the water chamber are measured with K-type thermocouples that display an uncertainty of $\pm 0.01 \mathrm{~K}$. The flow rate of the water $(\dot{m})$ is controlled with a needle valve and is measured with a flowmeter that has an uncertainty of $\pm 0.263 \mathrm{ml} / \mathrm{min}$. These data are used with (2) to accurately measure the actual heat transferred by the device

$$
q_{\text {out }}=\dot{m} c_{p}\left(T_{\text {out }}-T_{\text {in }}\right) .
$$

The uncertainty propagated in this calculation for $q_{\text {out }}$ yields $\pm 0.0767 \mathrm{~W}$. As shown in (2), q out is the heat removed by single-phase water loop, and $c_{p}$ is the specific heat of water. In order to evaluate the performance of the PFHP, ten K-type thermocouples are bonded to the test vehicle using high thermal-conductivity epoxy. The thermocouple distribution is shown in Fig. 7, and the readings are recorded by an Agilent data acquisition system (34970A) and then documented by a computer system. The entire test section is thermally insulated to reduce the heat loss due to natural convection and radiation.

\section{B. Results and Discussion}

The temperature distribution along the PFHP at various power inputs in the horizontal orientation is shown in Fig. 8. In these cases, the nominal input powers (heater power) are 3, 5, 8, 10 , and $13 \mathrm{~W}$. Because of the heat loss through natural convection and radiation, the actual heat powers transferred by the heat pipe are $2.85,4.71,7.50,9.11$, and $11.94 \mathrm{~W}$, respectively, which are estimated using (2). The temperature difference between the centers of the evaporator and the condenser

$$
\Delta T=T_{\text {evap }}-T_{\text {cond }}
$$




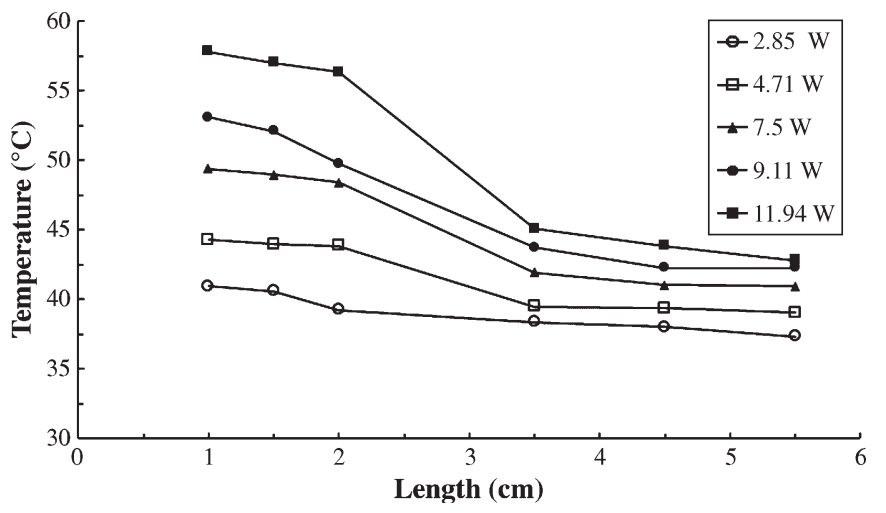

Fig. 8. Temperature distribution along the length of a working PFHP at various heat-transfer power levels, where the left side is the evaporator and the right side is the condenser.

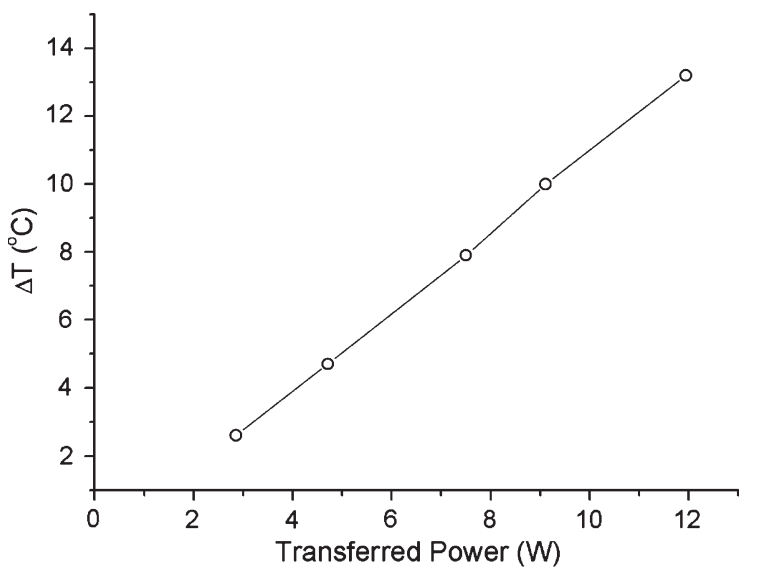

Fig. 9. Temperature difference between the evaporator and the condenser at various transferred power levels.

which is a standard method used to characterize the performance of heat pipes [9], is shown in Fig. 9.

It can be seen in the figure that the maximum temperature gradient across the evaporator is about $3 \mathrm{~K}$, and the maximum temperature gradient across the condenser is about $2 \mathrm{~K}$. This gradient is caused by condensate returning to the evaporator and absorbing the heat at the inner edge of the evaporator surface and, hence, lowering the temperature on that side. The opposite occurs at the inner edge of the condenser when the vapor gives off its latent heat of vaporization.

In order to evaluate the performance of PFHP, the effective thermal conductivity is generally employed to present the performance of the heat pipe and can be calculated using Fourier's law in

$$
k_{\mathrm{eff}}=\frac{q_{\mathrm{out}} L}{A \Delta T} .
$$

$L$ is the center-to-center distance between the condenser and the evaporator. $A$ is the cross-sectional area of the device.

It can be seen in Fig. 10 that the effective thermal conductivity of the PFHP is plotted as a function of input heat power and is in the range from 650 to $830 \mathrm{~W} / \mathrm{m} \cdot \mathrm{K}$ after the PFHP performance stabilized after $48 \mathrm{~h}$. The measured effective thermal conductivity of the PFHP is more than twice that of the pure copper reference sample (circle marker in Fig. 10). The

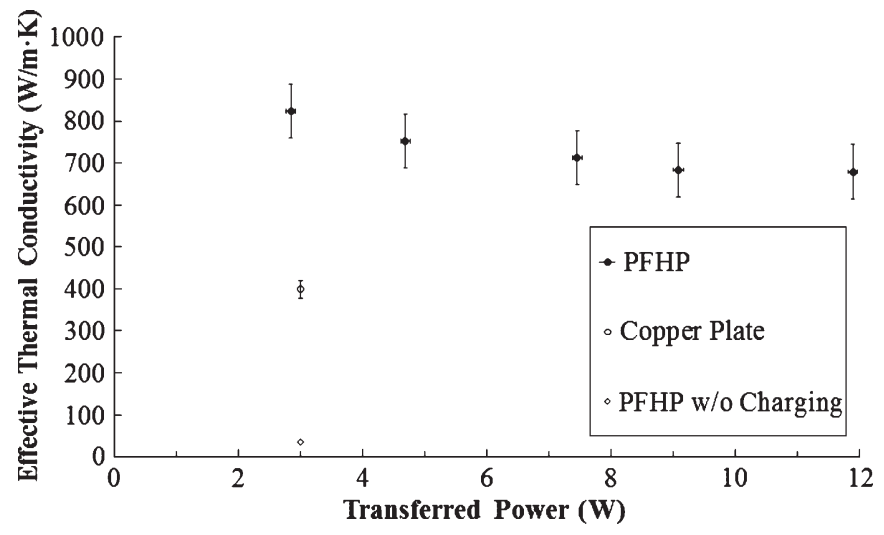

Fig. 10. Effective thermal conductivity of PFHP as a function of input power and compared with a copper-plate reference sample and an uncharged PFHP.

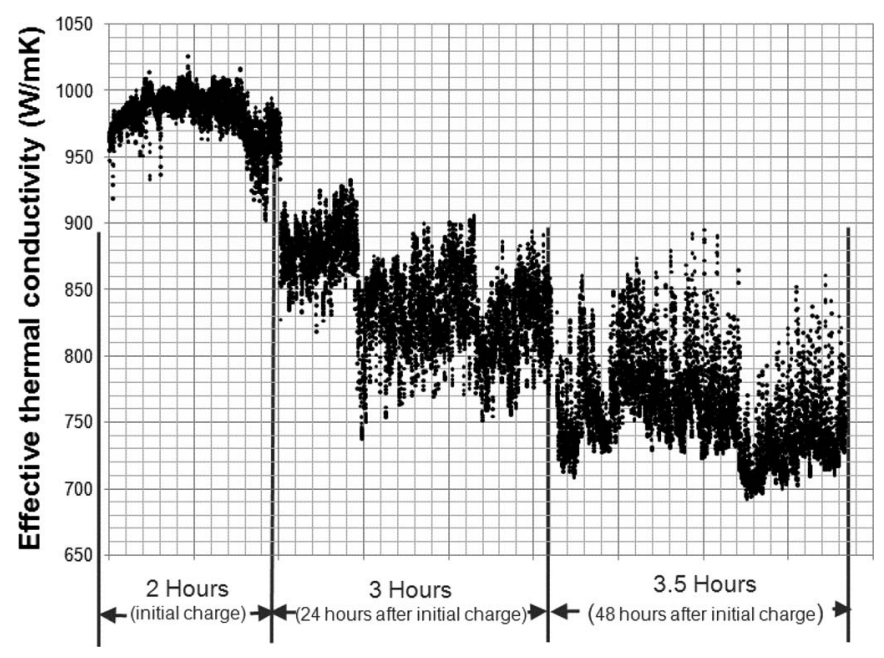

Fig. 11. Reliability test of PFHP over the span of $48 \mathrm{~h}$ after charging the device.

effective thermal conductivity of an empty (uncharged) heat pipe is also shown in Fig. 10 for comparison. For an uncharged heat pipe, heat is primarily transported from evaporator to condenser by thermal conduction. Since the polymer case is very poor in thermal conductivity, the majority of the heat is conducted along the copper frame, channels, and mesh. It is not surprising to clearly observe that the effective thermal conductivity of an uncharged heat pipe is much lower than an operational PFHP. This comparison validated that the PFHPs operates effectively and is superior to pure copper in terms of thermal conductivity.

A reliability test of the PFHP was also conducted. Fig. 11 shows that the effective thermal conductivity of PFHP has reached $1000 \mathrm{~W} / \mathrm{m} \cdot \mathrm{K}$ in the first $2 \mathrm{~h}$ after charging, and its performance degraded with time and stabilized around $750 \mathrm{~W} / \mathrm{m} \cdot \mathrm{K}$ after $48 \mathrm{~h}$. The PFHP still functions with relatively good performance after 48-h charging. The reasons for the performance degrading of the PFHP may come from several sources. The primary reason for this initial degradation may be a small quantity of noncondensing gas that gradually generates and accumulates during the operation. Second, the condensation area may become partially flooded, which would increase the thermal resistance on the condenser side. 


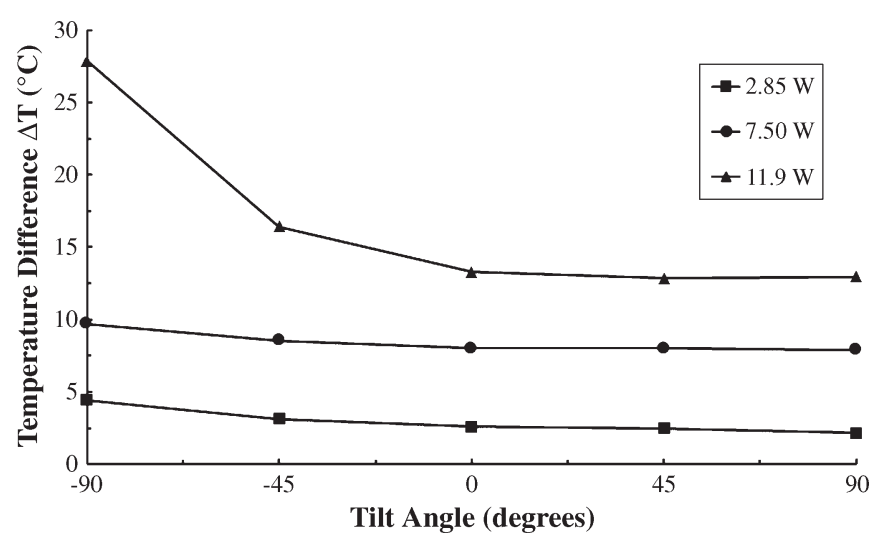

Fig. 12. Temperature difference $(\Delta T)$ between the evaporator and the condenser of the PFHP at various orientations of tilt angles, where $-90^{\circ}$ is adverse with the evaporator located above the condenser.

The test results showed that the PFHP developed in this study is a better thermal conductor and spreader than the pure copper plate in a range of working heat flux. Additionally, the weight of the PFHP is only one-tenth to one-fifth of the copper plate of the same dimensions.

The performance in different orientations requires investigation for applications in mobile electronics, such as laptop computers, personal digital assistants, mobile phones, or other portable electronic devices. Generally, heat-pipe performance varies significantly with its operating orientations [28], [29]. The position where the condenser is above the evaporator can enhance the liquid supply by assistance of gravity, which could result in high heat-transfer rate. However, when the evaporator is on top, gravity functions as additional pressure drop and causes a difficulty on the liquid supply, which in turn could cause premature partial or total dry out and degrade the heatpipe performance significantly. To evaluate the hybrid wicking structure of our PFHP in these adverse conditions, a rotatable setup is used to alter the tilt angle.

As shown in Fig. 12, for moderate input power of 3 and $8 \mathrm{~W}$, from the case of progravity $\left(90^{\circ}\right)$ to adverse gravity $\left(-90^{\circ}\right)$, the temperature difference between the evaporator and the condenser just slightly increases. This shows that the effectiveness of a hybrid wicking structure can generate higher capillary pressure compared with conventional heat pipes with uniform wicks and is able to overcome the gravitational hydrostatic pressure drop. Test results illustrate that this newly developed FPHP can work as high as $11.94 \mathrm{~W}$ at $1 g$ (adversegravity) acceleration and also demonstrate the effectiveness of hybrid wick structures.

\section{CONCLUSION}

A 1-mm-thick PFHP has been successfully developed, fabricated, and demonstrated. The performance of the PFHP at various input powers and orientations was measured and documented. The effective thermal conductivity of the PFHP reached as high as $830 \mathrm{~W} / \mathrm{m} \cdot \mathrm{K}$ with an input power range of 3.0-11.94 W in horizontal orientation, which is superior to existing FHPs in the same thickness range. The achieved high performance can be attributed to the careful control of vapor-core thickness and the development of hybrid wick structures made from woven copper mesh and microchannels. Additionally, copper-filled thermal vias were used to improve the thermal conduction through the LCP case. Although the tested prototype was assembled with a rigid frame and observation glass slide, the working substrate is flexible. With future development, PFHP employing LCP as the case material will offer the flexibility and capability to be integrated directly into PCBs as effective thermal-management solutions.

\section{ACKNOWLEDGMENT}

The views, opinions, and/or findings contained in this paper/ presentation are those of the authors/presenters and should not be interpreted as representing the official views or policies, either expressed or implied, of the Defense Advanced Research Projects Agency or the Department of Defense. Approved for public release with distribution unlimited.

\section{REFERENCES}

[1] M. Lallemand and F. Lefevre, "Micro/mini heat pipes for the cooling of electronic devices," in Proc. 13th Int. Heat Pipe Conf., Shanghai, China, 2004, pp. 12-23.

[2] L. L. Vasiliev, "Micro and miniature heat pipes-Electronic component coolers," Appl. Therm. Eng., vol. 28, no. 4, pp. 266-273, Mar. 2008.

[3] J. S. Go, "Quantitative thermal performance evaluation of a cost-effective vapor chamber heat sink containing a metal-etched microwick structure for advanced microprocessor cooling," Sens. Actuators A, Phys., vol. 121, no. 2, pp. 549-556, Jun. 2005.

[4] A. Basiulis, H. Tanzer, and S. McCabe, "Thermal management of high power PWB's through the use of heat pipe substrates," in Proc. 6th Annu. Int. Electron. Packag. Conf., San Diego, CA, 1986, pp. 501-515.

[5] Y. Wang and K. Vafai, "An experimental investigation of the thermal performance of an asymmetrical flat plate heat pipe," Int. J. Heat Mass Transf., vol. 43, no. 15, pp. 2657-2668, Aug. 2000.

[6] R. Boukhanouf, A. Haddad, M. T. North, and C. Buffone, "Experimental investigation of a flat heat pipe performance using IR thermal imaging camera," Appl. Therm. Eng., vol. 26, no. 17/18, pp. 2148-2156, Dec. 2006.

[7] G. Carbajal, C. B. Sobhan, G. P. Peterson, D. T. Queheillalt, and H. N. G. Wadley, "A quasi-3D analysis of the thermal performance of a flat heat pipe," Int. J. Heat Mass Transf., vol. 50, no. 21/22, pp. 42864296, Oct. 2007.

[8] R. Sonan, S. Harmand, J. Leger, and M. Fakes, "Transient thermal and hydrodynamic model of a flat heat pipe for the cooling of electronics components," Int. J. Heat Mass Transf., vol. 51, no. 25/26, pp. 6006-6017, Dec. 2008.

[9] A. Faghri, Heat Pipe Science and Technology. Washington, DC: Taylor \& Francis, 1995.

[10] M. Adami and B. Yimer, "Development and evaluation of a planar heat pipe for cooling electronic systems," Chem. Eng. Commun., vol. 90, no. 1, pp. 57-74, 1990.

[11] T. Ogushi, M. Murakami, H. Masumoto, and H. Yoshida, "Study on newly developed heat pipe heat sink," in Proc. ASME Nat. Heat Transf. Conf., Houston, TX, 1988, pp. 517-521.

[12] T. Shimura, H. Sho, and Y. Nakamura, "The aluminum flat heat pipe using cyclopentane as working fluid," in Proc. Int. Soc. Conf. Therm. Phenom., 2002, pp. 224-229.

[13] B. R. Babin, G. P. Peterson, and D. Wu, "Steady-state modeling and testing of a micro heat pipe," Trans. ASME, J. Heat Transf., vol. 112, no. 3, pp. 595-601, Aug. 1990.

[14] T. P. Cotter, "Principles and prospects of micro heat pipes," in Proc. 5th Int. Heat Pipe Conf., Tsukuba, Japan, 1984, pp. 328-335.

[15] S. H. Moon, G. Hwang, H. G. Yun, T. G. Choy, and Y. Kang, "Improving thermal performance of miniature heat pipe for notebook PC cooling," Microelectron. Reliab., vol. 42, no. 1, pp. 135-140, Jan. 2002.

[16] Y. Wang and G. P. Peterson, "Investigation of a novel flat heat pipe," Trans. ASME, J. Heat Transf., vol. 127, no. 2, pp. 165-170, Feb. 2005.

[17] H. T. Lim, S. H. Kim, H. D. Im, K. H. Oh, and S. H. Jeong, "Fabrication and evaluation of a copper flat micro heat pipe working under 
adverse-gravity orientation," J. Micromech. Microeng., vol. 18, no. 10, pp. 1-8, Oct. 2008.

[18] D. McDaniels and G. P. Peterson, "Investigation of polymer based micro heat pipes for a flexible spacecraft radiator," in Proc. ASME Int. Mech. Eng. Congr. Expo., New York, 2001, pp. 423-433.

[19] W. Y. Liu, S. Mohammadi, and L. P. B. Katehi, "Polymer micro heat pipe for InP/InGaAs integrated circuits," in Proc. 19th IEEE SEMI-THERM Symp., 2003, pp. 82-87.

[20] W. K. Jones, Y. Liu, and M. Gao, "Micro heat pipes in low temperature cofire ceramic (LTCC) substrates," IEEE Trans. Compon. Packag. Technol., vol. 26, no. 1, pp. 110-115, Mar. 2003.

[21] W. Wits, R. Legtenberg, J. Mannak, and B. van Zalk, "Thermal management through in-board heat pipes manufactured using printed circuit board multilayer technology," in Proc. Int. Electron. Manuf. Technol., Putrajaya, Malaysia, 2006, pp. 55-61.

[22] K. Jayaraj and B. Farrell, "Liquid crystal polymers and their role in electronic packaging," Adv. Microelectron., vol. 25, pp. 15-18, 1998.

[23] X. Wang, J. Engel, and C. Liu, "Liquid crystal polymer (LCP) for MEMS: Processes and applications," J. Micromech. Microeng., vol. 13, no. 5, pp. 628-633, Sep. 2003.

[24] E. C. Culbertson, "A new laminate material for high performance PCBs: Liquid crystal polymer copper clad films," in Proc. 45th Electron. Compon. Technol. Conf., 1995, pp. 520-523.

[25] B. Hand, T. Long, B. C. Dems, and F. Rodriguez, "Reactive ion etching of selected polymers in $\mathrm{O}_{2}$ and in $\mathrm{CF}_{4} / \mathrm{O}_{2}$, , J. Appl. Polym. Sci., vol. 47, no. 12, pp. 2135-2142, Mar. 1993.

[26] C. J. Oshman, B. Shi, C. Li, R. G. Yang, Y. C. Lee, and V. M. Bright, "Fabrication and testing of a flat polymer micro heat pipe," in Proc. Int. Solid-State Sens., Actuators, Microsyst. Conf., TRANSDUCERS, Denver, CO, 2009, pp. 1999-2002.

[27] D. D. Odhekar and D. K. Harris, "Experimental investigation of bendable heat pipes using sintered copper felt wick," in Proc. 10th Intersoc. Conf. Therm. Thermomech. Phenom. Electron. Syst., 2006, pp. 570-577.

[28] J. Esarte and M. Domiguez, "Experimental analysis of a flat heat pipe working against gravity," Appl. Therm. Eng., vol. 23, no. 13, pp. 16191627, Sep. 2003.

[29] Y. Cao, M. Gao, J. Beam, and B. Donovan, "Experiments and analysis of flat miniature heat pipes," J. Thermophys. Heat Transf., vol. 11, no. 2, pp. 158-164, 1997.

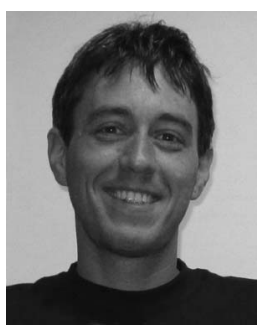

Christopher Oshman received the B.S. and M.S. degrees in mechanical engineering from the New Jersey Institute of Technology, Newark, NJ, in 1999 and 2002, respectively. He is currently working toward the Ph.D. degree in the Department of Mechanical Engineering, University of Colorado at Boulder.

His research interests include microfabrication and thermal/fluid modeling.

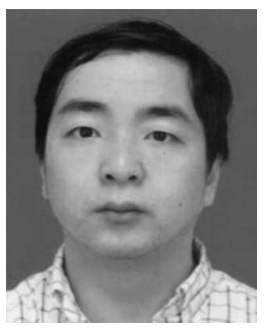

Bo Shi received the B.S. and M.S. degrees in mechanical engineering from Tsinghua University, Beijing, China, in 1999 and 2001, respectively, and the $\mathrm{Ph} . \mathrm{D}$. degree in mechanical engineering from the University of California, Los Angeles, in 2006.

$\mathrm{He}$ is currently an Associate Professor in the School of Energy and Power Engineering, Nanjing University of Science and Technology, Nanjing, China. His research interests include phase-change heat transfer on micro/nanostructures and their applications in high-efficiency thermal management, renewable green energy, and energy storage and transportation.

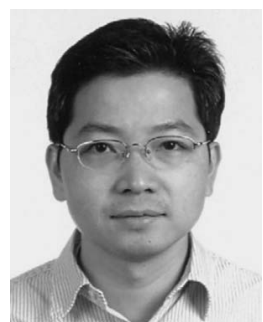

Chen $\mathbf{L i}$ received the B.S. degree in thermal engineering from Chongqing University, Chongqing, China in 1997, the M.S. degree in mechanical engineering from the University of Nevada, Reno, in 2003, and the Ph.D. degree in mechanical engineering from Rensselaer Polytechnic Institute, Troy, NY, in 2006.

$\mathrm{He}$ is currently an Assistant Professor in the Department of Mechanical Engineering, University of South Carolina, Columbia. He has been invited to serve as a Guest Editor for a special issue on "Micro/nano Transport Phenomenon in Renewable Energy and Energy Efficiency" of Advances in Mechanical Engineering and has authored or coauthored over 30 journal papers and peer-reviewed conference papers. His research interests are micro/nanoengineered materials and structures, heat and mass transfer associated with phase change, and their applications in renewable energy, energy efficiency, and thermal management.

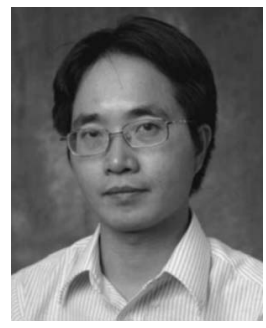

Ronggui Yang (M'01) received the B.S. degree from Xi' an Jiaotong University, Xi' an, China, in 1996, the M.S. degree in thermal engineering from Tsinghua University, Beijing, China, in 1999, the M.S. degree from the University of California, Los Angeles, in 2001, and the Ph.D. degree from the Massachusetts Institute of Technology, Cambridge, in 2006.

$\mathrm{He}$ is currently with the University of Colorado, Boulder, as an Assistant Professor in the Department of Mechanical Engineering, where his also a Sanders Faculty Fellow. His current research interests are nanoscale and ultrafast thermal sciences and their applications in energy and information technologies.

Dr. Yang's innovative research has won him numerous awards. He was the recipient of the Bergles-Rohsenow Young Investigator Award in Heat Transfer from the American Society of Mechanical Engineers (ASME) in 2010, a National Science Foundation CAREER Award in 2009, the Technology Review's TR35 Award in 2008, the Defense Advanced Research Projects Agency Young Faculty Award in 2008, the Goldsmid Award from the International Thermoelectrics Society in 2005, and a number of Best Paper awards and nominations from ASME and IEEE.

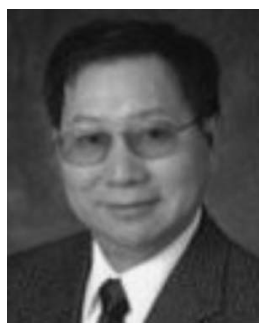

Y. C. Lee received the B.S. degree from National Taiwan University, Taipei, Taiwan, in 1978, and the M.S. and Ph.D. degrees from the University of Minnesota, Minneapolis, in 1982 and 1984, respectively.

He was a Member of Technical Staff with AT\&T Bell Laboratories, Murray Hill, NJ. He is currently a Professor of mechanical engineering at the University of Colorado at Boulder. His research activities include packaging and thermal management of multichip modules, 3-D packaging, self-aligning soldering, fluxless or solderless flip-chip connections, optoelectronics packaging, process control using fuzzy-logic models, MEMS, molecular biology integrated with micro/nanoscale technologies, and atomic layer deposition for integrated MEMS/NEMS. He was an Associate Editor of the ASME Journal of Electronic Packaging from 2001 to 2004.

Dr. Lee is an ASME Fellow. He was a Guest Editor for the IEEE TRANSACTION ON ADVANCED PACKAGING for two special issues on Packaging of MEMS/NEMS in 2003 and 2005. He was the recipient of a National Science Foundation Presidential Young Investigator Award in 1990. 


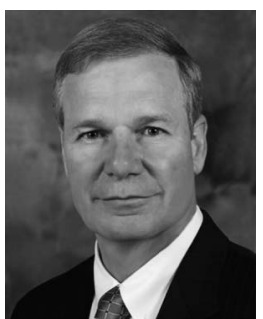

G. P. "Bud" Peterson received the B.S. degree in mechanical engineering, the B.S. degree in mathematics, and the M.S. degree in engineering from Kansas State University, Manhattan, in 1975, 1977, and 1980, respectively, and the Ph.D. degree in mechanical engineering from Texas A\&M University, College Station, in 1985.

He was a Chancellor of the University of Colorado at Boulder; a Provost of Rensselaer Polytechnic Institute (RPI), Troy, NY, from 2000 to 2006; and a Program Director of the National Science Foundation for the Thermal Transport and Thermal Processing Program from 1993 to 1994. He has held various positions with Texas A\&M University, beginning in 1981 as an Assistant Professor of engineering technology, Halliburton Professor of Mechanical Engineering in 1990, College of Engineering's Tenneco Professor, Head of the Department of Mechanical Engineering from 1993 to 1996, Executive Associate Dean of Engineering from 1996 to 2000, and Associate Vice Chancellor for Engineering of the Texas A\&M University System from 1996 to 2000 . He is the author or coauthor of 14 books or book chapters, 180 refereed journal articles, and more than 150 conference publications. He is the holder of eight patents with two others pending. His research interests have focused on the fundamental aspects of phase-change heat transfer, including the heat transfer in reduced-gravity environments, boiling from enhanced surfaces, and some of the earliest work in the area of flow and phase-change heat transfer in microchannels.

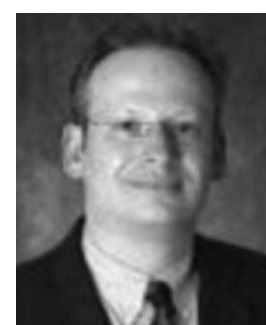

Victor M. Bright (S'89-M'92-SM'07) received the B.S. degree from the University of Colorado at Denver, in 1986, and the M.S. and Ph.D. degrees from the Georgia Institute of Technology, Atlanta, in 1989 and 1992, respectively.

$\mathrm{He}$ is a Professor and the Department Chair of Mechanical Engineering at the University of Colorado at Boulder and is the author of more than 100 refereed journal articles in the field of MEMS and microsystems. His research activities include MEMS, silicon micromachining, microsensors and microactuators, optoelectronics, ceramic MEMS, MEMS reliability, and MEMS packaging.

Dr. Bright is a Fellow of the American Society of Mechanical Engineers, served on the Technical Program Committee of the IEEE MEMS 2000-2006 Conferences, and was the General Cochair for the IEEE MEMS 2005 International Conference. He also served on the Technical Program Committees for Transducers'03, Transducers'07, IEEE/LEOS Optical MEMS 2003-2005, and the Hilton Head 2008 Solid-State Sensors and Actuators Workshop. $\mathrm{He}$ also taught a Short Course on MEMS Packaging at Transducers'03 and Transducers' 05 . 